são utilizados como recurso clínico em dentes tratados endodonticamente e com grandes perdas de estrutura dentinária. Este trabalho tem como objetivo demonstrar técnicas de blindagem e restaurações com recursos de alta performance, não protéticos, aplicados por profissionais.

Descrição do caso clínico: Neste trabalho são apresentados casos clínicos de blindagem corono-radicular, pós tratamento endodôntico. A metodologia empregada após a conclusão da endodontia foi o preparo dos retentores (acorde Machado 2015) com limas modificadas e posteriormente iniciou-se o processo de Blindagem. A limpeza do conduto foi realizada com raspagem e fricção de algodão com álcool fixados em uma lima 80 tipo k, para a remoção do cimento obturador remanescente e desidratação das paredes de dentina. Isto posto, aplicou-se por 30 segundos o sistema adesivo (MultilinkIvoclar Vivadent), valendo-se de microbrush. O preparo dos pinos de fibra de vidro (Angelus) foi realizado através de uma limpeza com álcool 70\% e, para melhorar a penetração do adesivo aos pinos, foi realizada aplicação de silano. Posteriormente foi aplicado sistema adesivo (Multilink Ivoclar - Vivadent) e os pinos cimentados com cimento resinoso químico (Multilink - Ivoclar Vivadent). Concluída a ação, os elementos foram restaurados com resina composta fotopolimerizável - (Direct Empress - Ivoclar Vivadent) (caso 1), reanatomizados e transformados em pilares para reabilitação protética (caso 2).

Discussão: $O$ dente tratado endodonticamente merece cuidados especiais, particularmente com respeito a sua restauração. No entanto, não há critérios bem definidos que podem resolver todos os casos, devido à grande variedade de casos e situações onde os dentes são submetidos na cavidade oral. Nos casos apresentados, a utilização de pinos de fibra de vidro representa uma alternativa viável, principalmente por boas propriedades mecânicas e estéticas dos mesmos.

Conclusão: Tal procedimento clínico estabeleceu uma forma de preservação da estrutura radicular, aumento da resistência a fratura e retenção, o que resultou na recuperação funcional e estética da estrutura dentária.

http://doi.org/10.24873/j.rpemd.2017.12.193

\#SPE-06 Segundo Pré-molar Inferior com Três Raízes: Caso Clínico

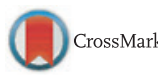

Gustavo Pereira, Tiago Paiva*, Miguel Pereira, Miguel Pinto

Pós-Graduação em Endodontia, CESPU- Cooperativa de Ensino Superior Politécnico e Universitário, Gandra; Estudante da Especialização em Endodontia, Faculdade Medicina Dentária Da Universidade do Porto; Instituto do Sorriso DreamClinic; Máster em Endodontia - Universidade Internacional da Catalunha, Barcelona

Introdução: A presença de variações anatómicas deve ser considerada antes de iniciar um tratamento endodôntico (TE). A presença de um elevado número de canais e raízes em pré-molares mandibulares, dificulta a execução do TE. O presente caso clínico demonstra o TE realizado num segundo pré-molar inferior (SPMI) com três raízes e três canais.

Descrição do Caso Clínico: O paciente masculino com 51 anos de idade, raça caucasiana, apresentava dores no $4 .^{\circ}$ quadrante. O diagnóstico provável foi de pulpite irreversível no dente 4.5. A análise da radiografia periapical revelou uma dimensão cervical superior ao normal, assim como a presença de uma anatomia canalar pouco frequente, presença de três raízes e três canais radiculares com divisão no terço médio. A cavidade de acesso foi modificada de modo a revelar a presença de dois canais vestibulares e um lingual. O TE foi realizado utilizando um localizador de ápex e sistema de limas Reciproc Blue. A obturação realizou-se através de condensação lateral.

Discussão: Os pré-molares mandibulares têm sido descritos como dentes desafiantes em endodontia, devido à grande variação do sistema de canais radiculares. A maioria dos SPMI possui uma única raiz com um único canal. A presença de duas ou mais raízes nestes dentes possui uma prevalência muito baixa, cerca de $0.4 \%$. A realização de radiografias anguladas, modificação de cavidade de acesso e utilização de magnificação são essenciais para o tratamento deste tipo de casos clínicos. A realização de CBCT pré-operatório está indicada. No caso clínico apresentado, a realização de radiografias anguladas, assim como adaptação da cavidade de acesso permitiu a identificação da anatomia canalar. A utilização de magnificação e sistema de limas com grande flexibilidade foram essenciais para a realização do TE.

Conclusões: O Médico Dentista deve estar atento e reconhecer as variações anatómicas do sistema de canais radiculares. A identificação e tratamento de canais acessórios permitem o sucesso do tratamento endodôntico.

http://doi.org/10.24873/j.rpemd.2017.12.194

\#SPE-07 Tratamento endodôntico com abordagem de canal calcificado - Caso Clínico

\section{Salomé Ferreira}

\section{Consulta de Endodontia do Hospital Privado de Alfena}

Introdução: Os processos de inflamação crónica como a cárie dentária provocam a obliteração do sistema de canais radiculares, o que pode constituir um problema com a localização e manipulação do canal durante o tratamento endodôntico.

Descrição do Caso Clínico: Paciente do sexo masculino, 40A, foi referenciado em Setembro de 2013 para tratamento endodôntico não cirúrgico do dente 35 após tentativa de acesso ao canal. Apresentava-se com sintomatologia dolorosa espontânea e foi estabelecido o diagnóstico de necrose pulpar e periodontite apical aguda. Sem antecedentes relevantes na história médica. Procedeu-se à remoção de todo o tecido cariado e acesso ao canal com pontas ultrassónicas Start-X com recurso à ampliação por meio de lupas. O glidepath foi efetuado com limas manuais e PathFile. O canal foi preparado quimicomecanicamente utilizando o sistema Protaper Universal e irrigação com hipoclorito de sódio 5,25\%. A obturação foi realizada com guta-percha e TopSeal pela técnica híbrida de Tagger. Após controlo de 3 anos, o dente encontra-se assintomático e em função.

Discussão e Conclusões: A localização e negociação dos canais calcificados são considerados um grande desafio durante a abordagem endodôntica. Na tentativa de localização dos canais podem ocorrer erros de procedimento, como perfurações, fraturas de instrumentos e desvios do trajeto original do canal. Atualmente, vários recursos clínicos são utilizados para auxiliar estes procedimentos, como radiografias, meios de ampliação e ultras- 